
substratos. Horticultura Brasileira 24: 241-244.

\title{
Produção de minitubérculos a partir de brotos de batata em diferentes combinações de substratos
}

\author{
Ernani Clarete da Silva ${ }^{1}$; Andressa B Giusto ${ }^{2 ; 3}$; José Alberto C de Sousa Dias ${ }^{2}$ \\ ${ }^{1}$ UNIFENAS, C. Postal 23, 70130-000 Alfenas-MG; E-mail: clarsil@ bol.com.br; ${ }^{2}$ IAC/APTA, Campinas-SP; E-mail: \\ andresagiusto@terra.com.br ${ }^{3}$ Bolsista FUNDAG
}

\section{RESUMO}

O presente trabalho teve como objetivo estudar cultivares e substratos na produção de minitubérculos de batata a partir de brotações de batata-semente. O delineamento experimental utilizado foi o de blocos ao acaso, em esquema fatorial $7 \times 3$, com três repetições. Os fatores estudados foram sete formulações de substrato com as seguintes proporções volumétricas: (1) terra autoclavada; (2) terra autoclavada + Plantmax (2:1); (3) terra autoclavada + fibra de coco (2:1); (4) fibra de coco; (5) Plantmax; (6) Plantmax + casca de arroz carbonizada (2:1) e (7) vermiculita e três cultivares de batata (Asterix, Monalisa e Ágata), fornecedoras de brotos. Os substratos Plantmax e fibra de coco e os brotos originados das três cultivares de batata são viáveis para este tipo de propagação.

Palavras-chave: Solanum tuberosum, brotações, batata-semente, propagação.

\begin{abstract}
Production of potato minituber by sprouts grown in several substrate combinations

Several types of substrates were evaluated for seed-potato minituber production of three cultivars, using sprouts as a propagation material. The experimental design was of randomized blocks distributed on a $7 \times 3$ factorial model containing three replicates of each treatment. Seven substrate types were evaluated: (1) autoclaved soil; (2) autoclaved soil + Plantmax (2:1); (3) autoclaved soil + coconut fiber (2:1); (4) coconut fiber; (5) Plantmax; (6) Plantmax + carbonized rice shell (2:1); and (7) vermiculite and the potato cultivars Asterix, Monalisa and Ágata. The substrates Plantmax and coconut fiber and the sprouts originated from the tree potato cultivars are viable for this propagation type.
\end{abstract}

Keywords: Solanum tuberosum, sprouts, seed potato, propagation.

\section{(Recebido para publicação em 27 de abril de 2005; aceito em 10 de maio de 2006)}

$\mathrm{N}_{\mathrm{b}}^{\circ}$ sistema de produção da batata brasileira, sempre houve dependência da batata-semente importada de países como Holanda, Alemanha e Suécia, onde as condições climáticas dificultam o desenvolvimento de viroses (Sousa-Dias \& Costa, 1984; Sousa-Dias et al., 1993). As viroses da cultura da batata constituem-se entre as principais dificuldades enfrentadas pelos produtores, uma vez que causam degenerescência da batata-semente, com queda significativa da produtividade geração após geração. Em razão das condições adversas, sobretudo na produção do tubérculo-semente, as importações representam significativo montante em dólar que evadido do país anualmente (6 a 9 milhões). Em 2002-2003, segundo a ABBA (Associação Brasileira da Batata), citada por Batata Show (2003), as importações foram de $2.734,52$ toneladas com $52,50 \%$ deste total proveniente da Holanda e o restante do Canadá, Chile, Escócia, França e Alemanha. A aplicação de técnicas de cultura de tecidos vegetais, visando a produção em larga escala de plantas isentas de patógenos, em especial vírus, vem sendo utilizada desde a década de 50 como alternativa para solucionar o problema da falta de material propagativo com alta qualidade fitossanitária (Castro, 1991). Entretanto, apesar da eficiência destas técnicas, é importante a realização de testes de indexação para os principais vírus ocorrentes na região durante todo o processo produtivo. Segundo Medeiros et al. (2000), a produção de sementes básicas e certificadas através de cultura de tecidos, inicia-se com a produção de plantas in vitro, que, após um período de aclimatização, são transferidas para telados onde produzirão os tubérculos na primeira etapa do processo de produção de sementes prébásicas. Nos telados, além da necessidade de desinfestação do solo com produtos químicos, normalmente danosos ao meio ambiente, a produtividade alcançada é bastante baixa, não ultrapassando cinco tubérculos por planta. Por outro lado a propagação da batata feita principalmente por via vegetativa, através de tubérculos apresenta desvantagens quanto ao armazenamento, transporte, quantidade necessária ao plantio e sanidade, o que pode comprometer até
$50 \%$ da produtividade (Medeiros, et al., 2001a). Segundo Medeiros et al. (2001a, 2001b) e Pereira et al. (2001), os resultados até então alcançados no Brasil com a produção de tubérculos em sistemas hidropônicos indicam um importante avanço no processo produtivo de sementes de batata, contribuindo para aumentar a taxa de multiplicação de tubérculos pré-básicos. No Brasil, usualmente, os brotos de batata-semente importada são descartados como prática fitotécnica executada antes do plantio para aumentar a taxa de multiplicação dos lotes. A ausência da dominância apical dos brotos removidos acaba por promover uma melhor brotação dos tubérculos. Como este material é livre de viroses, a utilização do mesmo tem sido considerada uma técnica promissora na produção de minitubérculos de batata-semente. Os brotos podem ser plantados em vasos, canteiros ou bandejas dentro de telados anti-afídeos, de forma bastante prática, versátil e a baixo custo. Cada broto origina uma média de três minitubérculos, de tamanhos que podem superar $5 \mathrm{~cm}$ de diâmetro. Esses minitubérculos somam-se aos lotes de batata-semente 
Tabela 1. Número e massa de minitubérculos produzidos por brotos em função dos substratos e das cultivares de batata. Alfenas, UNIFENAS/IAC, 2003**

\begin{tabular}{lcc}
\hline \multirow{2}{*}{ Substrato } & \multicolumn{2}{c}{ Minitubérculo } \\
\cline { 2 - 3 } & Número & Massa (g) \\
\hline Plantmax & $5,44 \mathrm{a}$ & $10,49 \mathrm{a}$ \\
Fibra de coco & $5,29 \mathrm{~b}$ & $6,75 \mathrm{bc}$ \\
Vermiculita & $4,99 \mathrm{bc}$ & $5,67 \mathrm{bc}$ \\
Plantmax + casca de arroz carbonizada & $4,77 \mathrm{bc}$ & $8,12 \mathrm{ab}$ \\
Terra autoclavada + Plantmax & $4,18 \mathrm{bc}$ & $4,67 \mathrm{bc}$ \\
Terra autoclavada + Fibra de coco & $4,07 \mathrm{c}$ & $5,08 \mathrm{bc}$ \\
Terra autoclavada & 2,36 & $\mathrm{~d}$ \\
\hline Cultivares & & $0,62 \mathrm{~d}$ \\
\hline Ágata & $5,79 \mathrm{a}$ & $4,46 \mathrm{~b}$ \\
Monalisa & $4,34 \mathrm{~b}$ & $6,44 \mathrm{a}$ \\
Asterix & $3,20 \mathrm{c}$ & $6,85 \mathrm{a}$ \\
\hline CV (\%) & 18,57 & 3,43 \\
\hline
\end{tabular}

*As médias seguidas por letras distintas na vertical diferem entre si ao nível de $5 \%$ indicado pelo teste de Tukey.

nacional de alta sanidade (classe básica), podendo ser plantados diretamente no campo, com resultados de produtividade e sanidade semelhantes aos obtidos com os originados do plantio feito com batata-semente importada ou básica nacional (Sousa-Dias \& Costa, 1998).

A batateira é uma planta herbácea cuja parte subterrânea do caule é formada pelos estólons (pseudocaule) que dão origem aos tubérculos nas suas extremidades (Párraga \& Cardoso, 1981). Por conseguinte, as propriedades físicas do solo sob cultivo da batata assumem grande importância, sendo preferíveis àqueles de textura média, não muito argilosos nem compactos, que possibilitem um ótimo desenvolvimento de raízes, estólons e tubérculos (Filgueira, 1999).

Substratos são meios onde se desenvolvem as raízes das plantas cultivadas fora do solo (Carneiro, 1995) e constituem-se de formas comerciais de pronto uso, que podem ser acrescidos de materiais como casca de arroz carbonizada, vermiculita, terra de barranco, húmus e outros (Faquim \& Vilela, 1996), melhorando o seu rendimento (Nannette \& Souza, 1998), e as sua propriedades físicas. Portanto, um substrato agrícola deve guardar uma proporção adequada entre macro e microporos. Esta característica favorece a atividade fisiológica das raízes e, conseqüentemente, o desenvolvimento das plantas (Fernandes et al., 2002), principalmente em plantas cujo produto comercial se desenvolve subterraneamente.
O objetivo deste trabalho foi estudar o efeito de cultivares e diferentes composições de substratos na produção de minitubérculos de batata a partir de brotações de batata-semente importada.

\section{MATERIAL E MÉTODOS}

O experimento foi conduzido nas dependências da UNIFENAS, de 14/05/ 03 a 11/08/03. Utilizou-se uma estrutura de proteção de $85 \mathrm{~m}^{2}$ (17 m x $\left.5 \mathrm{~m}\right)$, modelo capela, com cobertura de plástico transparente de 100 micra de espessura aditivada contra raios ultravioletas. O delineamento experimental utilizado foi de blocos ao acaso, em esquema fatorial $7 \times 3$ com três repetições. Os fatores estudados foram sete formulações de substrato nas seguintes proporções: (1) terra autoclavada; (2) terra autoclavada + Plantmax (2:1); (3) terra autoclavada + fibra de coco (2:1); (4) fibra de coco; (5) Plantmax; (6) Plantmax + casca de arroz carbonizada (2:1) e (7) vermiculita e três cultivares de batata-semente importadas, fornecedoras de brotos (Asterix, Monalisa e Ágata). Estas cultivares, amplamente cultivadas no Brasil, são apropriadas para cozimento (Ágata e Monalisa) e com excelentes qualidades para fritura na forma de batata palha e palito (Melo, 1999; Batata Show, 2001). Os brotos, com média de 2 a $3 \mathrm{~cm}$ de comprimento apresentavam alta sanidade, livres de viroses cuja verificação foi feita na Universidade Fe- deral de Lavras. Posteriormente, estes brotos foram plantados em sacolas de plástico com capacidade de 1,8 L. O substrato Plantmax HT empregado foi um produto compostado e estabilizado com cascas processadas e enriquecidas, vermiculita expandida, turfa processada e enriquecida, desenvolvido especificamente para a produção de mudas de solanáceas e brássicas; O substrato fibra de coco W 47 empregado foi um formulado a partir de $100 \%$ de fibra de coco, de textura fina, indicado principalmente para formação de mudas em bandejas e tubetes; O Bio Rica Vermiculita foi um substrato composto à base de vermiculita, enriquecido com microorganismos benéficos, composto vegetal e fosfato natural; A casca de arroz carbonizada foi obtida pela incineração em incinerador de fogo brando; A terra autoclavadafoi obtida de terra de barranco, latossolo vermelho de textura areno-argilosa submetida à temperatura de $121^{\circ} \mathrm{C}$ em autoclave. Nenhum tipo de adubo foi acrescido aos substratos. Os tratos culturais e fitossanitários foram feitos conforme o recomendado para a cultura. Foram avaliados o número de minitubérculos por plantas, seu peso médio e produção de minitubérculos por planta. Os dados obtidos foram submetidos à análise de variância, sendo as médias comparadas pelo teste de Tukey ao nível de 5\% de probabilidade.

\section{RESULTADOS E DISCUSSÃO}

Para a característica número de minitubérculos por planta não houve interação significativa entre os fatores substratos e cultivares analisados. Por outro lado, estes fatores apresentaram isoladamente diferenças altamente significativa. Os brotos oriundos da cultivar Ágata foram os que produziram a maior quantidade de minitubérculos aptos a serem usados como semente (Tabela 1), enquanto os substratos Plantmax e fibra de coco apresentaram significativamente os melhores desempenhos na avaliação desta característica (Tabela 1). Dias et al. (2003), avaliando o desempenho das cultivares de batata Ágata, Vivaldi, Asterix e Atlantic, observaram que a cultivar Ágata produziu 31,32 hastes por $\mathrm{m}^{2}$ enquanto as de- 
mais cultivares produziram de 4,29 a 10,2 hastes por $\mathrm{m}^{2}$. Também observaram que o maior número de hastes correspondeu a maior número de tubérculos. De acordo com Fontes \& Finger (1999), quanto maior o número de hastes por $\mathrm{m}^{2}$, maior o número de tubérculos por planta e, conseqüentemente, maior a produção da cultura. Contudo, o excesso de hastes pode resultar em produção de tubérculos pequenos, já que as mesmas competem entre si por nutrientes e reservas nutritivas. Provavelmente esta característica tenha se manifestado também na produção de minitubérculos através de brotos. Em termos práticos, esta característica é importante já que o número de tubérculos-semente irá influir significativamente no custo de produção. A cultivar Asterix e o substrato terra autoclavada foram os fatores que apresentaram os piores resultados para a produção de minitubérculos (Tabela 1).

Para peso de minitubérculos também não foi verificada interação significativa entre os fatores substrato e cultivares. As cvs. Asterix e Monalisa apresentaram os minitubérculos com maior peso, sendo observado que o pior desempenho foi verificado com a cv. Ágata (Tabela 1). Este fato se justifica em função desta cultivar ter produzido o maior número de minitubérculos, conseqüentemente, tendo reduzido o tamanho. Em termos de batata-semente, o peso médio dos tubérculos é importante já que são preferíveis aqueles com peso inferior e de menor tamanho (Filgueira, 1999), pois rendem mais no plantio com conseqüente redução no custo de produção. Como o objetivo é produzir minitubérculos-semente, o número produzido é mais importante que o peso. Quanto aos substratos, o melhor desempenho relacionado a esta característica foi verificado com Plantmax e Plantmax + casca de arroz carbonizada, que produziram 10,49 e 8,12 minitubérculos em média, por sacola, respectivamente. O pior desempenho foi em terra autoclavada com 0,62 minitubérculo, por sacola (Tabela 1).

Considerando a produção de minitubérculos por planta houve interação significativa entre os fatores cultivares e substratos (Tabela 2). A cv.

Tabela 2. Minitubérculos produzidos por planta em gramas originárias de brotos em função de substratos e da cultivar. Alfenas, UNIFENAS/IAC, 2003.*

\begin{tabular}{|c|c|c|c|}
\hline \multirow{2}{*}{ Subs trato } & \multicolumn{3}{|c|}{ Cultivar } \\
\hline & Monalisa & Ágata & Asterix \\
\hline Plantmax & $75,27 \mathrm{aA}$ & $55,07 \mathrm{aB}$ & $36,17 \mathrm{aC}$ \\
\hline Plantmax + Casca de arroz carbonizada & 33,74 bA & $41,17 \mathrm{abA}$ & $30,62 \mathrm{aA}$ \\
\hline Fibra de Coco & 36,44 bA & $28,81 \mathrm{bcA}$ & $36,60 \mathrm{aA}$ \\
\hline Vermiculita & 28,00 bA & 27,31 bcA & $25,29 a A$ \\
\hline Terra Autoclavada + Fibra de Coco & 23,94 bA & $19,70 \mathrm{cdA}$ & $16,67 a b A$ \\
\hline Terra Autoclavada + Plantmax & $15,99 \mathrm{bcA}$ & $22,11 \mathrm{bcdA}$ & $15,99 a b A$ \\
\hline Terra Autoclavada & $2,04 \quad c A$ & 1,59 & 0,74 bA \\
\hline $\mathrm{CV} \%$ & 23,2 & & \\
\hline
\end{tabular}

*As médias seguidas por letras distintas minúsculas na vertical e maiúsculas na horizontal diferem entre si ao nível de $5 \%$ indicado pelo teste de Tukey.

Monalisa e o substrato Plantmax produziram os melhores resultados para esta característica. A produção individual da planta é um dado que, para produção de sementes, deve ser avaliado sempre correlacionado com o número de tubérculos. Os tubérculos devem apresentar peso suficiente para garantir um bom estande da cultura e produzir grande quantidade. Filgueira (1999) relata que para desenvolver uma haste principal, cada gema requer um peso mínimo em termos de substância tuberosa na batata mãe, que é o mesmo, quando se utiliza a batata-semente miúda ou graúda. Por outro lado, a Portaria $\mathrm{n}^{0} 154$ de 23/07/87 do Ministério da Agricultura, publicada no Diário Oficial da União de 24/07/87, estabelece para batata-semente certificada, apenas um tamanho máximo de tubérculo que deve estar entre 50 e $60 \mathrm{~mm}$ de diâmetro. Não existe, portanto, um tamanho mínimo especificado, e a classe V abrange todos os tubérculos-semente menores que $23 \mathrm{~mm}$. Kawakami et al. (2003) compararam a produção proveniente de microtubérculo-semente com peso variando de 0,5 a $1,0 \mathrm{~g}$ e 1,0 a $3,0 \mathrm{~g}$ com tubérculo-semente convencional de 50 g. Observaram que a produção das plantas provenientes dos micro-tubérculos foi apenas $18 \%$ inferior à produção das plantas provenientes de semente convencional e concluíram que os microtubérculos têm potencial para o uso em campo. O substrato Plantmax, a mistura Plantmax + casca de arroz carbonizada e Plantmax + pó de coco têm sido utilizados com sucesso na produção de mudas de hortaliças (Silva et al., 1997;
Ferreira et al., 2002; Silveira et al., 2002). Por outro lado, Andriolo et al. (1999) caracterizaram e avaliaram substratos para o cultivo de tomateiro fora do solo. Observaram que o substrato Plantmax e a casca de arroz carbonizada apresentaram uma densidade significativamente menor que húmus e a mistura casca de arroz e solo. Exclusivamente para recipientes fechados, como sacolas de plástico, esta característica é importante já que indica um meio mais leve, com quantidades de macro e micro poros adequados, melhor arejamento e menor compactação, características indispensáveis ao bom desenvolvimento de tubérculos.

As cultivares de batata avaliadas (Monalisa, Asterix e Ágata) são aptas para produção de minitubérculos através de brotações e os substratos Plantmax e fibra de coco são mais indicados para este fim.

\section{REFERÊNCIAS}

ANDRIOLO JL; DUARTE TS; LUDKE L; SKREBSKY EC. 1999. Caracterização e avaliação de substratos para cultivo do tomateiro fora do solo. Horticultura Brasileira 17: 215-219.

Batata Show. A revista da batata.2001. 1: 1. 39p. Batata Show. A revista da batata. 2003. 3: 7. 41p. CARNERO JGA. 1995. Produção e controle de qualidade de mudas vegetais. Curitiba: UFPR/ FUPEF. 451p.

CASTRO LL. 1991. Cultivo de tejidos para la producción de semilla básica de papa. In: ROCA WM; MROGINSKI LA (eds). Cultivo de tejidos en la agricultura: Fundamentos e Aplicaciones. Colombia: CIAT. p. 447-468.

DIAS GS; SILVA EC; MACIEL GM. 2003. Competição de cultivares de batata na Região de Alfenas-MG. In: CONGRESSO BRASILEIRO DE OLERICULTURA, 43. Resumos...Recife: SOB (CD-ROM). 
FAQUIM VAEF; VILELA LAA. 1996. Produção de alface em hidroponia. Lavras: UFLA, 50p.

FERNANDES C; ARAUJO JAC; CORÁ EJ. 2002. Impacto de quatro substratos e parcelamento da fertirrigação na produção de tomate sob cultivo protegido. Horticultura Brasileira 20: 559-563.

FERREIRA WR; RANAL MA; FILGUEIRA FAR. 2002. Fertilizantes e espaçamentos entre plantas na produtividade da Couve-daMalásia. Horticultura Brasileira 20: 635-640.

FILGUEIRA FAR. 1999. Práticas culturais adequadas em bataticultura. Informe Agropecuário 20: 34-41.

FONTES PCR; FINGER FL. 1999. Manejo póscolheita da batata. Informe Agropecuário 20: 105-111.

KAWAKAMI J; IWAMA K; HASEGAWA T; JITSUYAMA Y. 2003. Growth and yield of potato grown from microtubers in fields. American Journal of Potato Research 80: 371 378.

MEDEIROS CAB; ZIEMER AH; PEREIRAAS; DANIELS J. 2000. Estrutura de sistema hidropônico para produção de sementes prébásicas de batata. Pelotas: Embrapa Clima Temperado. 10p. (Comunicado Técnico, 29).
MEDEIROS CAB; DANIELS J; PEREIRA AS. 2001. Produção de sementes pré- básicas de batata em sistema hidropônico: Multiplicação a partir de plântulas produzidas in vitro. In: CONGRESSO BRASILEIRO DE OLERICULTURA, 41. Resumos... Brasília: SOB (CD-ROM).

MEDEIROS CAB; DANIELS J; PEREIRA AS. 2001. Produção de sementes prébásicas

de batata em sistema hidropônico: Multiplicação a partir de minitubérculos. In: CONGRESSO BRASILEIRO DE OLERICULTURA, 41. Resumos... Brasília: SOB (CD-ROM).

MELO PE. 1999. Cultivares de batata potencialmente úteis para processamento na forma de fritura no Brasil e manejo para obtenção de tubérculos adequados. Informe Agropecuário 20: 112-119.

MINISTÉRIO DAAGRICULTURA, PORTARIA $\mathrm{N}^{0} 154$ DE 23 DE JULHO DE 1987. Diário Oficial da União de 24 de Julho de 1987.

NANNETTI DC; SOUZA RJ. 1998. A cultura do pimentão. Boletim Técnico. Ano VII, n. 31, Lavras: UFLA. 52p.

PÁRRAGA MS; CARDOSO MRO. 1981. Botânica, taxonomia e espécies cultivadas de batata. Informe Agropecuário 20: 10-12.
PEREIRA JES; MEDEIROS CAB; FORTES GRL; DANIELS J; PEREIRA AS. 2001. Avaliação de dois sistemas hidropônicos para a produção de sementes pré-básicas de batata. In: CONGRESSO BRASILEIRO DE OLERICULTURA, 41. Resumos... Brasília: SOB (CD-ROM).

SILVA EC; ALVARENGA MAR; CARVALHO JG. 1997. Produção e podridão apical do tomateiro (Lycopersicon esculentum Mill) podado e adensado sob influência da adubação nitrogenada e potássica. Ciência. e Agrotecnologia 21: 324-333.

SILVEIRA EB; RODRIGUES VJLB; GOMES AMA; MARIANO RLR; MESQUITA JCP. 2002. Pó de coco como substrato para produção de mudas de tomateiro. Horticultura Brasileira 20: 211-216.

SOUZA-DIAS JAC; COSTA AS. 1984. Método “cova/pré-plantio" na seleção de batata-semente. Campinas: Fundação Cargill. 68p.

SOUZA-DIAS JAC; COSTAAS. 1998. O produtor pode fazer a sua própria batata-semente. A Granja a Revista do Líder Rural. 54: 12-18.

SOUZA-DIAS JAC; COSTA AS; NARDIN AM 1993. Potato leafroll virus in solanaceous weeds in Brazil explains severe outbreaks of the disease in absence of known potato donor sources. Summa Phytopathologica 19: 80-85. 